PACS: 42.79.Pw, 68.55 Ac

\title{
Research of structures with corrugated photoreceiving surface
}

\author{
A.V. Karimov, D.M. Yodgorova, E.N. Yakubov \\ Physical-Technical Institute of the Scientific Association "Physics-Sun" of the Academy of Sciences of the Republic \\ of Uzbekistan, Tashkent, Mavlanova 2b, Tashkent 700084 (fax 998+712+354291). \\ E-mail: karimov@physic.uzsci.net
}

\begin{abstract}
Goffered photoreceiver surface in active regions perspective for manufacturing photosensitive structures can be form by chemical and epitaxial technology. Microreliefs are created on initial surface of semiconductor material by chemical method that comprises etching in special solutions. Epitaxial technology allow to obtain goffered layers on etched surface and on the smooth one as well using growth from a liquid phase. In the case of smooth surfaces, chosen are parameters of solutionmelt providing the growth of the layer. The structures with the formed goffered surface have high photosensitivity and a wide optical range for their operation.
\end{abstract}

Keywords: epitaxial technology, microrelief, photoreceiver, chemical etching.

Manuscript received 28.07.04; accepted for publication 16.12.04.

\section{Introduction}

The efficiency of optical signal transformation of in the electrical one by using photoconverters depends, first of all, on properties of the surface of active regions and the potential barrier interface. They determine the photosensitivity and optical operation range of the photoconverter structure. The microrelief as well as transparent coatings are usually created on the photoconvertor surface to reduce losses caused by reflections $[1,2]$. Besides, to increase an effective area of the potential barrier, where photocarriers are divided, it is possible to get the appropriate microreliefat the interface. Thus, the method of such a microrelief creation can be applied to obtain a high efficiency by increasing the effectiveness of the potential barrier interface and that of the photoreceiver surface.

The appropriate relief in photoconverter structures can be created by primary chemical processing the initial crystals or selection of their cryctallographic orientation. The morphology of epitaxial layer surface depends on accuracy of the substrate orientation as concerning the plane where growing the layer is carried out. When growing the epitaxial GaAs layers by the gas transport method, it was revealed that the small deviations $(0.5$ to $1.5^{\circ}$ ) from the crystallographic orientation result in formation of growth steps perpendicular axis $<100>$ of the substrate. Moreover, at partial oxidation of the substrate surface by etching island origination can take place [3].

A relief surface can be also prepared using epitaxial escalation of AlGaInAs layers on GaAs [4] in a horizontal graphite shear boat at the temperature $800{ }^{\circ} \mathrm{C}$. The increase of the In concentration more than $10 \%$ results in strips arising on the surface of layers. In any case, there remains a problem of controllable management of parameters of microrelief and its sizes.

In this report, the results of studying the structures with goffered photoreceiver surface on the base InGaAs obtained by the liquid phase epitaxy method are reported.

\section{Experimental}

To prepare the goffered structures, we used GaAs substrates of 400 -micron thickness, with the area $10 \times 10$ $\mathrm{mm}^{2}$ oriented in thecrystallographic direction $\langle 100\rangle$ and those having the deviation by $3^{\circ}$ as well. The carrier concentration in the initial crystal was $3 . . .5 \cdot 10^{15} \mathrm{~cm}^{-3}$.

Morphology of the structure surface has been researched before chemical-technological processes and also after them by the microscope MIM-7 and by the electronic microscope EMV-100L at the magnification with 3000 up to 10000 -fold magnification.

The researches of the substrate morphology have shown that it is possible to remove partially defects from their surface and to create the certain microrelief (Fig. 1,b). For this purpose, GaAs substrates with the deviation by $3^{\circ}$ were processed in the etchant $3 \mathrm{HNO}_{3}+1 \mathrm{HF}+1 \mathrm{H}_{2} \mathrm{O}_{2}$ and those oriented in the crystallographic direction $\langle 100\rangle$ were done by etching with $5 \mathrm{H}_{2} \mathrm{SO}_{4}+\mathrm{H}_{2} \mathrm{O}_{2}+\mathrm{H}_{2} \mathrm{O}$ for 20 to $30 \mathrm{~s}$, then they were washed out in $\mathrm{CCl}_{4}$ and dried in deionized water. 


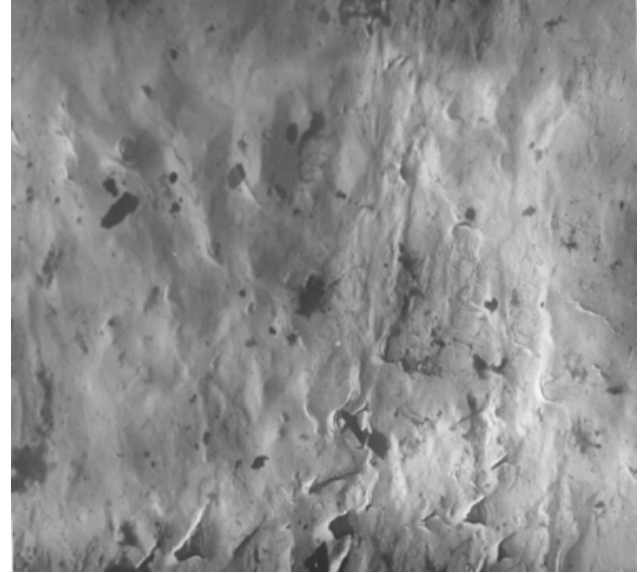

Fig. 1a. Sample of type N 2. 5300. Substrate before etching.

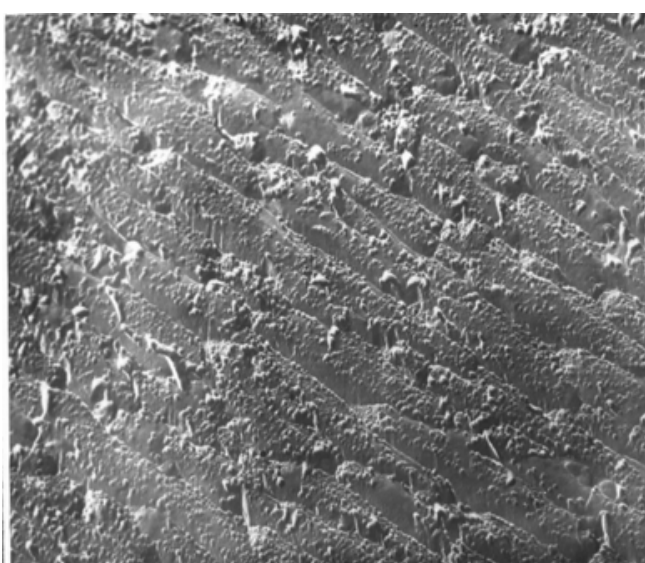

Fig. 2a. Magnification $10125^{\times}$. Substrate N 2 with orientation $<100>$ after etching with quasi-lattice surface.

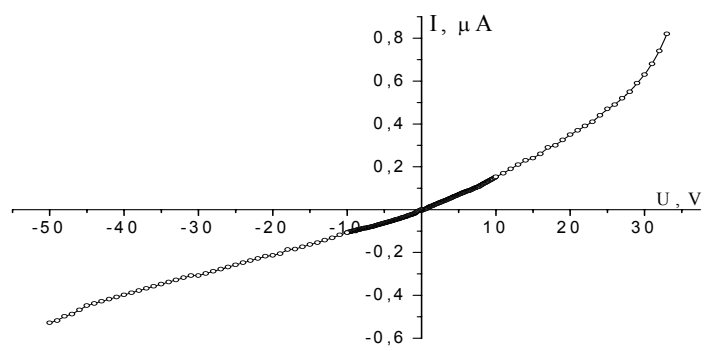

Fig. 3. Current-voltage characteristic of $\mathrm{m} / \mathrm{p}$-GaAs $/ n-\mathrm{Ga}_{0.94} \mathrm{In}_{0.06} \mathrm{As} / \mathrm{m}$-structure with goffered photoreceiver surface.

Typical morphology of GaAs crystals surface manufactured by etching are given in Figs 1 and 2. The surface of the ferst type samples has the certain microrelief, and that of the second type samples has a quasilattice microrelief. In the samples of the second type (with quasilattice morphology of the surface) the

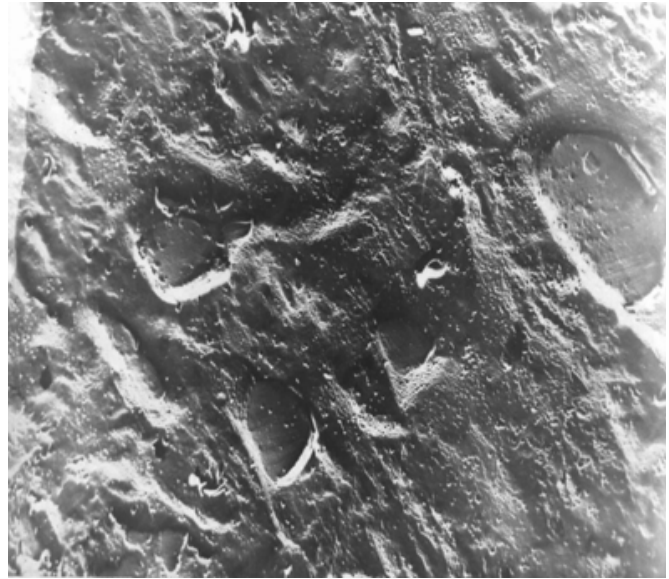

Fig. 1b. Sample of type N 1. $3680^{\times}$. Substrate with deviation $3^{\circ}$ from $<100>$ orientations after etching

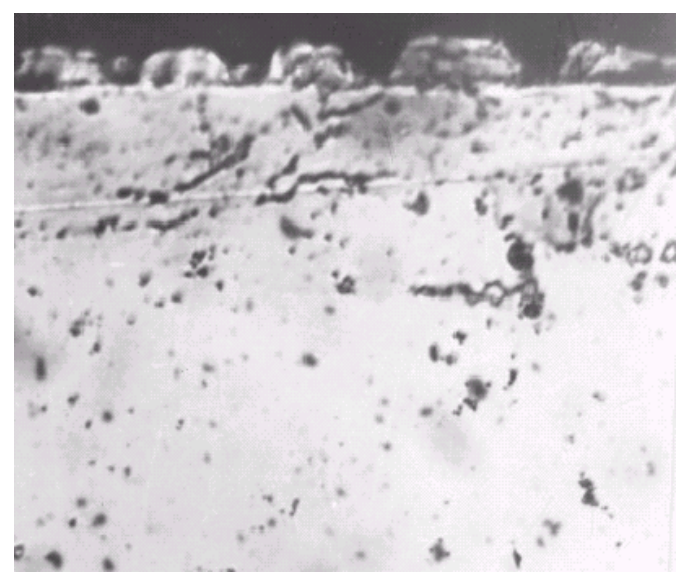

Fig. 2b. Magnification $8100^{\times}$. Morphology of epitaxy $n$ - $\mathrm{Ga}_{0.94} \mathrm{In}_{0.06}$ As layer, grown on GaAs substrate.

depth of strips was 0.8 to $1.0 \mu \mathrm{m}$, and the width of the strips was 0.08 to $1.0 \mu \mathrm{m}$.

The researches of optical properties of substrates prepared by this method have shown that the reflection coefficient has small values in the visible spectrum, especially for the structures with quasilattice surface. So, the reflection coefficient in the shortwave range $(\lambda=0.2 \ldots 0.3 \mu \mathrm{m})$ decreases from 36 down to $10 \%$.

Epitaxial $n$ - $\mathrm{Ga}_{0.94} \mathrm{In}_{0.06} \mathrm{As}$ layer grown by compulsory cooling from the liquid phase on these etched substrates had the look of goffer (Fig. 2b).

\section{Results and discussion}

Precipitation of $\operatorname{In}_{\mathrm{x}} \mathrm{Ga}_{1-\mathrm{x}}$ As solutions on GaAs substrates was carried out from a limited volume of the $(\mathrm{Ga}+\mathrm{In}+\mathrm{GaAs})$ solution-melt by compulsory cooling (non-isothermal liquid epitaxy) in the graphite container of a "pencil-box" type placed into an open type reactor blown through the flow of cleaned hydrogen. Doped by tellurium GaAs monocrystals with carriers concentration 


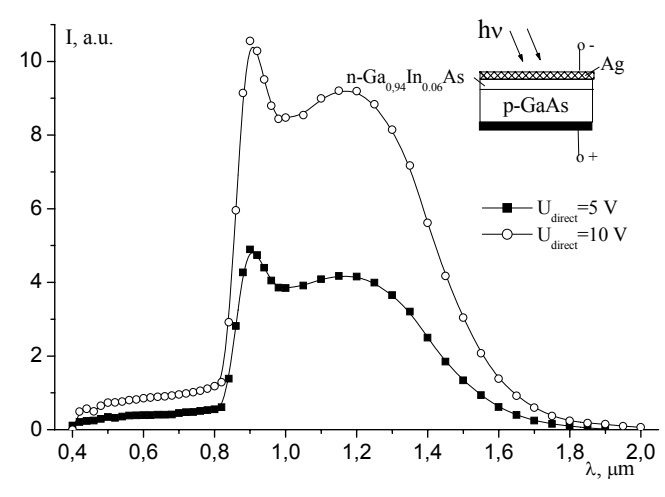

a

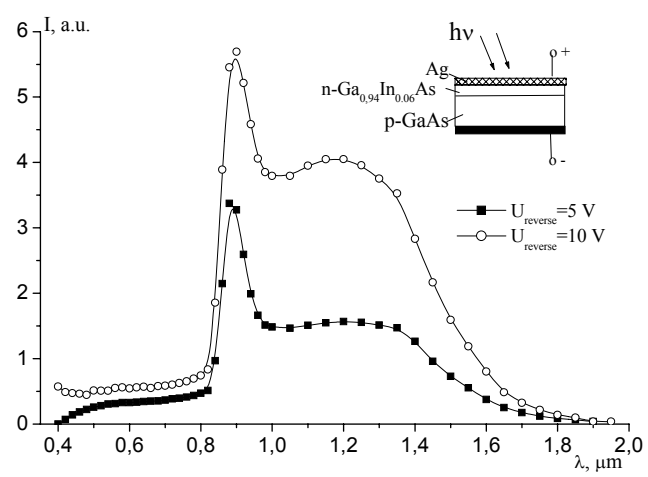

$\mathrm{b}$

Fig. 4. Spectral characteristics of the $m / p-G a A s / n-G a_{0.94} \mathrm{In}_{0.06} \mathrm{As} / m$ structure at two values of forward (a) and reverse (b) voltages.

$\sim 10^{17} \mathrm{~cm}^{-3}$ were used as a source for the solution-melt.

The researches have been shown that at formation of In contained layers at the constant cooling speed the surface morphology changes very much. Particulary, even at the small content $(0.1$ at. $\%)$ the layers grown at $750 \ldots 840{ }^{\circ} \mathrm{C}$ have the goffered surface with the distance between "peaks" from 2 up to $16 \mu \mathrm{m}$.

The good results were obtained at initial temperatures of crystallization taken from the range $750 \ldots 855^{\circ} \mathrm{C}$ by feed of the solution-melt every $5^{\circ} \mathrm{C}$.

The portions of the solution-melt were chosen approximately $4 \ldots 8$ microlayers at a process. The basic solution-melt was satisfied to the ratio $\mathrm{Ga} / \mathrm{GaAs}=16$. Thickness of the melt was chosen using the formula $h=2 \cdot 10^{-1}(D t)^{1 / 2}$, where, $D$ is the impurity diffusion coefficient, $t$ is the impurity diffusion length.

It's necessary to note that in this case, to avoid partial dilution of the substrate with microrelief after homogenization of the solution-melt, program cooling with speed $0.3{ }^{\circ} \mathrm{C}$ per minute was switched on, and then the substrates were put under the solution-melt. Initial temperature of epitaxy was about $830^{\circ} \mathrm{C}$.
The researches of the Hall effect have shown that prepared InGaAs epitaxial layers really have $n$-type of conductivity. The carrier concentration in the tellurium doped epitaxial layer was been $2 . .3 \cdot 10^{16} \mathrm{~cm}^{-3}$. Distances between peaks and height of peaks vary depending on the thickness of the epitaxial layer. On the surface of the epitaxial layer, a semitransparent $\mathrm{Ag}$ contact was deposited using thermal evaporation, and on the back side of the substrate Sn contact was formed. In structures with optimum parameters, the height of peaks reached $5 \ldots 7 \mu \mathrm{m}$, and the distance between peaks was approximately $5 \mu \mathrm{m}$.

When finishing the structure creation, chemicaltechnological processing and clearing the surfaces were carried out, and than the subsequent process of manufacturing the frontal and back contacts was made. On the surface of the epitaxial layer, the semitransparent Ag contact was deposited, and on the backside of the substrate Sn contact was formed.

The investigation of the current-voltage characteristics testifies to distinction between forward and reverse bias directions (Fig. 3).

\begin{tabular}{|c|c|c|l|l|l|l|l|}
\hline \multicolumn{2}{|c|}{$\begin{array}{c}\mathrm{N} \text { and type of a } \\
\text { sample, temperature } \\
\text { and time of etching }\end{array}$} & \multirow{2}{*}{$\begin{array}{c}\text { Morphology } \\
\text { of surface }\end{array}$} & \multicolumn{1}{|c|}{$0.2-0.3 \mu \mathrm{m}$} & $0.3-0.38 \mu \mathrm{m}$ & $0.38-0.48 \mu \mathrm{m}$ & $0.48-0.7 \mu \mathrm{m}$ \\
\cline { 5 - 8 } & $\mathrm{R}_{\max }-\mathrm{R}_{\min } \%$ & $\mathrm{R}_{\max }-\mathrm{R}_{\min }, \%$ & \multicolumn{1}{c|}{$\mathrm{R}, \%$} & \multicolumn{1}{c}{$\mathrm{R}, \%$} \\
\hline 1 & $24^{\circ} \mathrm{C}$ & $1 \mathrm{~min}$ & quasi-lattice & $42-19$ & $19-17$ & 17.5 & 11 \\
\hline 2 & $22^{\circ} \mathrm{C}$ & $1 \mathrm{~min}$ & quasi-lattice & $36-16.5$ & $16.5-15$ & 15.5 & 10 \\
\hline 3 & $24^{\circ} \mathrm{C}$ & $3 \mathrm{~min}$ & quasi-lattice & $45-21.5$ & $21.5-19$ & 20.5 & 14 \\
\hline 4 & $30^{\circ} \mathrm{C}$ & $1 \mathrm{~min}$ & quasi-lattice & $41-18$ & $18-17$ & 18 & 12 \\
\hline 5 & - & $30 \mathrm{~s}$ & dendrite & $52.5-20$ & $20-18.5$ & 18.5 & 17.5 \\
\hline 6 & - & $45 \mathrm{~s}$ & dendrite & $60-20$ & $20-18$ & 12.5 & 11.5 \\
\hline
\end{tabular}




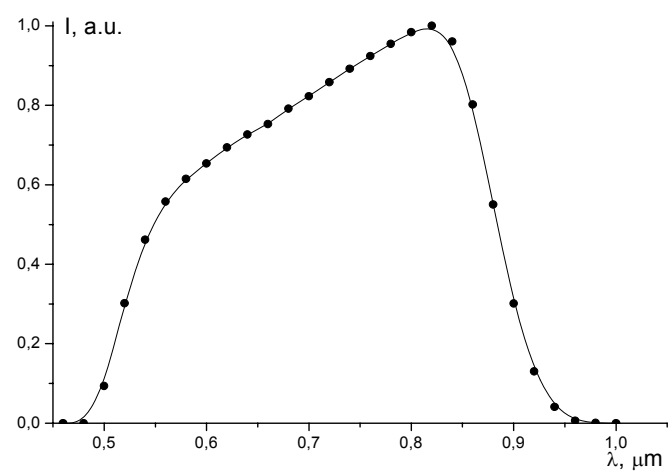

Fig. 5. Spectral characteristics of the structure with the heterojunction $p$-AlGaAs $/ p$-GaAs $/ n$-GaAs.

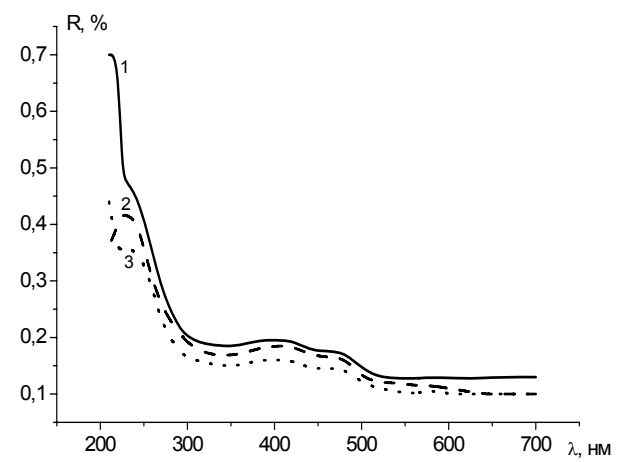

Fig. 6. Spectral dependences of the reflection coefficient inherent to the GaAs crystal: solid line - sample N 6, dashed curve - sample N 4, dotted curve - sample N 2.

In the forward direction, the current value increases exponentially up to $0.8 \mu \mathrm{A}$ with increasing the voltage up to $30 \mathrm{~V}$, and in the reverse direction current reaches $0.54 \mu \mathrm{A}$ at $50 \mathrm{~V}$. Application of the the positive voltage polarity to metal from the side of the $p$-GaAs substrate corresponds to the forward direction, so the operating $p-n$ junction takes place in this case.

The optical operating range of the researched structures comprises the interval from 0.4 up to $1.8 \mu \mathrm{m}$ (Fig. 4). As it can be seen from the Figs $4 \mathrm{a}$ and $4 \mathrm{~b}$, in the interval from 0.8 up to $1.5 \mu \mathrm{m}$ the photosensitivity is three and more times longer than in other parts of the spectrum. Increasing the forward voltage (Fig. 4a) as well as reverse one (Fig. 4b) results in the proportional increase in the photosensitivity of the structure, and the photosensitivity in the longwave part of the spectrum at the forward voltage is 2 to 3 times higher than that at the reverse voltage. It is characteristic that band-to-band excitation at the reverse voltage is expressed more precisely. Thus, in the shortwave range of the spectrum 0.4 to $0.8 \mu \mathrm{m}$ the photosensitivity increases with increasing the voltage. It testifies that the region of photocarrier separation comes nearer to the illuminated surface at the voltage. At forward voltage the intrinsic photosensitivity approach to the impurity photosensitivity $(1.0 \ldots 1.3 \mu \mathrm{m})$.

The comparison of the spectral characteristics of various structures testifies that each of them has their specific features. The structures with the Shottky barrier possess a high photosensitivity in the shortwave range of spectrum, and the sensitivity in that shortwave range increases with the applied voltage. On the contrary, the photosensitivity of typical $p$-AlGaAs $/ p$-GaAs $/ n-G a A s$ photoconvertor structures is higher in the longwave range (Fig. 5). The sensitivity is rather uniform in a wide spectral range for the structures with goffered surface.

The spectral dependences of the GaAs reflection coefficient for \#6, \#4, \#2 crystal samples are given in Fig. 6. Typical morphologies of GaAs crystal surface prepared by etching in the samples \#2 and \#4 are quasilattice and in the sample \#6 is dendrite. The research of the obtained substrate showed, that the reflection coefficient in the visible range (see Table) has small values on the quasilattice surface. The minimal value of the reflection coefficient obtained in the sample $\# 2$, when the time of etching is equal to 1 minute at the temperature $22^{\circ} \mathrm{C}$.

The results of researches of reflection coefficient in visible area of spectrum for several types of exemplars are given in the Table.

In particular, it was established, that in the samples with quasilattice morphology of surface and with the least optical reflection in the visible spectral range the depth of strips have made $(0.8 \ldots 1.0) \mu \mathrm{m}$, and the width of strips $(0.08 \ldots 1.0) \mu \mathrm{m}$. The reflection coefficient in the shortwave range have decreased from $36 \%$ down to $10 \%$ in the longwave spectral range, which can be seen more precisely in the Fig. 6.

Thus, it is possible to conclude that formation of microrelief in photoconvertor heterostructures should improve their spectral sensitivity in the shortwave spectral range. The optical operation range of structures based on $p$-GaAs $/ n \mathrm{Ga}_{0.94} \mathrm{In}_{0.06}$ does not coincide with that of known structures containing the $p-n$ junction or Shottky barrier.

\section{Conclusion}

Etching the surface of initial GaAs crystals makes it possible to form the dendritic microrelief or quasilattice one as flutes with 0.8 to $1.0 \mu \mathrm{m}$ depth and 0.08 to $1.0 \mu \mathrm{m}$ width. Similarly, at formation of epitaxial GaInAs layers by compulsory cooling from a liquid phase on etched substrates or at presence in them the distinctions in crystallographic operation it is possible to create goffered microrelief covers wider spectrum than those of structure with the $p-n$ junction or Shottky barrier. 


\section{References}

1. N.L. Dmitruk, O.Yu. Borkovskaya, R.V. Konakova, I.B. Mamontova, S.V. Mamikin, D.I. Voytsikhovskyi, Influence of a scale-irradiation on the characteristics of phototransformation of barrier structures metal - gallium arsenide with the microrelief by border undressed // Technical Physics Letters 72 (6), p. 44 (2002).

2. V.I. Shashkin, A.V. Murel, V.M. Daniltsev, O.I. Hrikin, Management of character transfer of current in a barrier Shottky with the help delta-alloyage: account and experiment for $\mathrm{Al} / \mathrm{GaAs}$ // Semiconductors 36 (5), p. 537 (2002).

3. T.Ya. Gorbach, E.V. Pidlisniy, S.V. Svechnikov, Morphology and properties of anisotropically etched gallium arsenide // Optoelectronics and semiconductor technics 13, p. 34-39 (1988) (in Russian).

4. P. Swarup, R.K. Jain, S.N. Verna, S. Charan, D.M. Tandle // J. Cryst. Growth. 63 (1), p. 97-104 (1983). 